\title{
A Systematic Review on Clinimetric Properties of Play Instruments for Occupational Therapy Practice
}

\author{
Muhammad Hibatullah Romli $\mathbb{D}^{1,2}$ and Farahiyah Wan Yunus ${ }^{3}$ \\ ${ }^{1}$ Department of Nursing and Rehabilitation, Faculty of Medicine and Health Sciences, Universiti Putra Malaysia, 43400 Serdang, \\ Selangor, Malaysia \\ ${ }^{2}$ Malaysian Research Institute on Ageing (MyAgeing), Universiti Putra Malaysia, 43400 Serdang, Selangor, Malaysia \\ ${ }^{3}$ Centre for Rehabilitation and Special Needs Studies, Occupational Therapy Programme, Faculty of Health Sciences, \\ Universiti Kebangsaan Malaysia, 50300 Kuala Lumpur, Malaysia \\ Correspondence should be addressed to Muhammad Hibatullah Romli; hibatullah.romli@gmail.com
}

Received 19 March 2020; Revised 24 April 2020; Accepted 16 June 2020; Published 1 August 2020

Guest Editor: Anna Berardi

Copyright (c) 2020 Muhammad Hibatullah Romli and Farahiyah Wan Yunus. This is an open access article distributed under the Creative Commons Attribution License, which permits unrestricted use, distribution, and reproduction in any medium, provided the original work is properly cited.

\begin{abstract}
Play is considered the main occupation for children. Pediatric occupational therapists utilize play either for evaluation or intervention purpose. However, play is not properly measured by occupational therapists, and the use of play instrument is limited. This systematic review was aimed at identifying play instruments relevant to occupational therapy practice and its clinimetric properties. A systematic search was conducted on six databases (Academic Search Complete, CINAHL, MEDLINE, Psychology and Behavioral Science Collection, Scopus, and ASEAN Citation Index) in January 2020. The quality of the included studies was evaluated using Law and MacDermid's Appraisal for Clinical Measurement Research Reports, and psychometric properties of play instruments were evaluated using Terwee's checklist while the clinical utility is extracted from each instrument. Initial search identifies 1,098 articles, and only 30 articles were included in the final analysis, extracting 8 play instruments. These instruments were predominantly practiced in the Western culture, which consists of several psychometric evidences. The Revised Knox Preschool Play Scale is considered the most extensive and comprehensive play instrument for extrinsic aspect, whereas the Test of Playfulness + Test of Environmental Supportiveness Unifying Measure is a promising play instrument for intrinsic aspect on play, where both instruments utilize observation. My Child's Play is a potential questionnairebased play instrument. However, the current development of play instruments in the occupational therapy field is immature and constantly evolving, and occupational therapists should exercise good clinical reasoning when selecting a play instrument to use in practice.
\end{abstract}

\section{Introduction}

Occupational therapy for children is found as one of the largest practice areas globally [1]. For children, play is the most important occupation that dominates their use of time. Play can be one of the therapeutic goals and can be used as a medium of intervention, which helps to improve an individual's functional performance [1-4]. Play was found to be beneficial for biological, physical, mental, and social development [5]. In general, play is a learning process that equips children with necessary physical, psychological, cognitive, and social skills to facilitate normal development for typical children [6]. Therefore, selecting the right play activities as a means or as an end is important to bring the optimal outcome of children.

Using standardized play assessment can facilitate practitioners in identifying appropriate play activities to be set either as a goal or as a medium of intervention. However, utilization of standardized occupational therapy play instrument even as a research outcome is limited either on occupational therapy intervention [7] or on play-based intervention $[2,3]$. An overview of reviews found no study that systematically identifies and investigates standardized occupational therapy instruments on play [8]. Several review 
studies were found during the literature search but were not in a systematic format. Stagnitti [6] listed three instruments: Knox Preschool Play Scale (and all its variation), Test of Playfulness, and Play History; however, the study was not systematically searched to identify any other play-based instruments. Sturgess [9] suggested several play instruments; however, only Play History and Preschool Play Scale were identified as occupational therapy-based instruments. Two reviews $[10,11]$ investigated functional assessments for children, and both identified that only the McDonald Play Inventory was used as an instrument tool for play. The limitation of the two reviews was the searching was limited to one journal platform. The absence of comprehensive review study as a guideline will hamper occupational therapy practitioners to efficiently use an appropriate play instrument and to plan an appropriate intervention.

Psychology, speech therapy, physiotherapy, and special education are other disciplines that have interest on play other than occupational therapy. Several instruments were developed by other professions, and several reviews investigated the psychometric properties of these instruments [12-14]. However, each discipline observed each aspect differently. Occupational therapy evaluates play itself, while other professions utilized play activity as a medium to evaluate a particular component [15]. For example, psychologists observe play to specifically evaluate the cognitive function and determine cognitive or social capacity $[13,14]$, and physiotherapists observe play to evaluate the physical capacity of children [12]. In addition, the only instrument-focused systematic review [12] investigated play-based assessment and not play assessment. Play-based assessment utilizes play activity but evaluates nonplay aspects, such as motor or cognitive functions, whereas play assessment evaluates play for the sake of play.

A study found that occupational therapists used various types of assessments to evaluate play, but some are not purported for play [16]. For example, majority of occupational therapists used Vineland Adaptive Behavior Scale and Battelle Developmental Inventory that evaluate adaptive behavior and general physical, cognitive, and social development in an intention to assess play. This may result in misled judgement on the intervention planning; there is evidence where play is used to elicit improvement in other areas, such as fine motor skills and cognitive function $[16,17]$. Therefore, difference on the philosophical foundation of instruments may hinder occupational therapists to efficiently conduct the evaluation and interpret the findings effectively for the purpose of play.

Kuhaneck and colleagues [16] indicated a decreasing trend of using play instrument among occupational therapists. Several reasons were mentioned such as lack of knowledge on available play instruments and lack of continuing education on the existing play instruments. Lynch et al. [18] in their survey found a similar finding where occupational therapists considered play important but indicated lack of education either from research, theory, evaluation, or intervention that contributed to challenges in applying play-centered practice. Meanwhile, Wadley and Stagnitti [19] found that occupational therapists and teachers do appreciate the importance of play for children; however, parents' and family members' understanding on the therapeutic value of play is limited and does not consider play the main goal for the children's functional outcome. Using standardized assessment is part of evidence-based practice [20], enhances the confidence, and strengthens communication and message delivery [21] on the importance of play. Therefore, a systematic review should be conducted to gather play assessments relevant for use in occupational therapy practice to inform the practitioners on the available instruments, enhance evidence-based practice, and select the best instrument for efficient communication medium with clients.

\section{Materials and Methods}

2.1. Study Objective. This systematic review was registered on INPLASY (Registration Number: 202040156) and PROSPERO (CRD42020170370). The aim of this review is to identify and gather clinimetric evidence of play instruments developed by occupational therapists. Clinimetric refers to the evidence of psychometric properties (i.e., validity and reliability) and clinical utility of an instrument [22].

2.2. Study Identification. A systematic search was conducted on six electronic databases, namely, Academic Search Complete, CINAHL, MEDLINE, Psychology and Behavioral Science Collection, Scopus, and ASEAN Citation Index. Keywords were generated by discussion among authors and reviewing previous literatures. The following keywords were used: ("play" OR "play-based” OR "playthings”) AND ("evaluation" OR "assessment" OR "measurement" OR "battery" OR “test” OR “instrument") AND ("validity" OR "reliability" OR "sensitivity" OR "precision” OR "specificity" OR "responsiveness" OR "psychometric") with slight variation. Boolean operators, parenthesis, truncation, and wildcards were used whenever appropriate. For ASEAN Citation Index, only the word "play" was keyed in as the limited function of the search engine that does not allow for search string to be implemented. As the search number was overwhelming, restriction was imposed on keywords existent only in the title for play-related keywords. The search was conducted on 21 January 2020.

Manual search was conducted by screening the reference list of the included study. In addition, the identified instruments were searched for its original article. An innovative method using the "cited by" option in Google Scholar was performed on all original and included articles to allocate more potential articles [23]. Relevant citations were then selected, and the screening process was conducted for eligibility.

2.3. Eligibility Criteria. Each retrieved study was evaluated for its eligibility according to the following inclusion and exclusion criteria. The inclusion criteria were (i) study on the instrument for leisure type of play (not competitive play or sports), (ii) instrument generally evaluating play, (iii) study investigating the psychometric property of the instrument, (iv) the instrument used solely on play (not part of a multidimensional instrument), and (v) the instrument relevant for 
the use of occupational therapy. The last criteria were determined by scrutinizing the instruments found either developed or involved occupational therapist by reviewing the authors of the instrument's original study. Exclusion criteria were (i) not a primary study (i.e., review and editor note), (ii) no full text available, (iii) full text is not available in English, (iv) grey literature (e.g., thesis, book, and conference), and (v) nonpeer review journal article.

2.4. Study Selection. Duplicates were initially removed before the screening process. The first author screened the title for eligibility according to the predetermined criteria, followed by independent screening of the abstract and full text by both authors. The preconsensus agreement was calculated by comparing the final accepted articles between the two authors. Any disagreements were resolved through discussion between the two authors until consensus was achieved.

2.5. Data Extraction and Analysis. Included articles in the final analysis were narratively analyzed. Each article is extracted for study objective, study design, instrument investigated, number and characteristics of raters, number and characteristics of participants, country of the study, and findings on psychometric property. Extracted play instruments were then identified on its clinical utility focused on the application and administration aspects.

2.6. Quality Appraisal of the Study. Two quality assessment tools were used. The quality of each article is assessed using a quality appraisal evaluation form by Law and MacDermid [24]. Terwee's checklist [25] is used to evaluate the pool of psychometric evidence on each instrument found. Although the COnsensus-based Standards for the selection of health status Measurement Instruments (COSMIN; [26]) is considered the gold standard to evaluate the quality of the assessment tool instrument, however, it has several limitations to be used in this systematic review. First, the COSMIN was specifically developed to assess articles demonstrating patient-reported outcomes of health measurement instruments, which might not be suitable for some occupational therapy measurement tools such as play instruments that are complex, varied in terms of administration procedures, involved observation or proxy for rating, and comprised environmental and ecological elements [17, 27, 28]. Second, while the validity of the COSMIN is adequate [29], the reliability of the COSMIN through kappa analysis was poor [30]. Therefore, the use of Law and MacDermid's form and Terwee's checklists is better suited for this study.

Quality Appraisal for Clinical Measurement Research Reports Evaluation Form [24] is a 12-item checklist evaluating the quality of psychometric study on five domains that are research question, design, measurements, analyses, and recommendations. Each item on this form is assigned a score of $0-2$ (2, best practice; 1 , acceptable but suboptimal practice; and 0 , substantially inadequate or inappropriate practice). Only item 6 can be denoted as N/A (not applicable) because it relates to the longitudinal type of study (i.e., test-retest). The total score is calculated by adding all scores from each item and then converted to a percentage. Higher score indi- cates better quality. The form was developed by rehabilitation experts from occupational therapy and physiotherapy backgrounds and has excellent interrater reliability [31-37] that has been used in environment-based instruments [28]. Quality assessments were administered by both authors and verified through discussion.

The Terwee checklist is an assessment tool to determine the quality of psychometric properties of the instrument [25]. For that purpose, studies were grouped based on the instrument described, and a summary of psychometric properties of each instrument was then prepared according to eight categories, namely, (i) content validity, (ii) internal consistency, (iii) criterion validity, (iv) construct validity, (v) reproducibility (agreement and reliability), (vi) responsiveness, (vii) floor or ceiling effect, and (viii) interpretability. Each instrument was then assessed against the quality criteria and rated according to four categories: positive (i.e., +), which means having a desired outcome with robust methodology; intermediate (i.e., ?), which means having a desired outcome with less robust methodology; poor (i.e., -), means having an undesired outcome or having poor methodology; and no information available (i.e., N/A). When two or more studies investigated the same property, the highest quality score for that item was recorded.

\section{Results}

A total of 1,098 articles were retrieved; 1,043 were obtained from the electronic database search, and another 55 were later identified from the reference list of the included studies and list of relevant literature found using Google Scholar's "cited by" option. Ultimately, as shown in Figure 1, 63 [38$100]$ articles were excluded during the full-text screening and 30 [101-130] individual studies were selected after the screening process by the two authors (preconsensus agreement on accepted full text: 79.4\%). The description of each included individual study and its psychometric report is presented in Table 1.

Quality of individual studies was measured using Law and MacDermid's Quality Appraisal Tool, and the result is presented in Table 2. Overall, studies have the median score quality of $65.5 \%$ (range, $45-86 \%$ ).

Eight original occupational therapy play instruments were extracted from the 30 included articles. The included instruments are (i) Child-Initiated Pretend Play Assessment (ChIPPA; including Indigenous Play Partner Scale), (ii) Revised Knox Preschool Play Scale (Knox PPS), (iii) McDonald's Play Inventory (MDPI), (iv) My Child's Play (MCP), (v) Play Assessment for Group Setting (PAGS), (vi) Playform, and (vii) Play History Interview (PHI) and Test of Playfulness (ToP, including Test of Environmental Supportiveness (TOES) and ToP-TOES Unifying Measure (TTUM)). One occupational therapy instrument-Play Skills Inventory [38] - was found but was not included as there is no published journal article that investigated its psychometric property. Some of the instruments were published only once (i.e., McDonald's Play Inventory, My Child's Play, Playform, Play History Interview, and Play Assessment for Group Setting), whereas some were reported in several articles in 


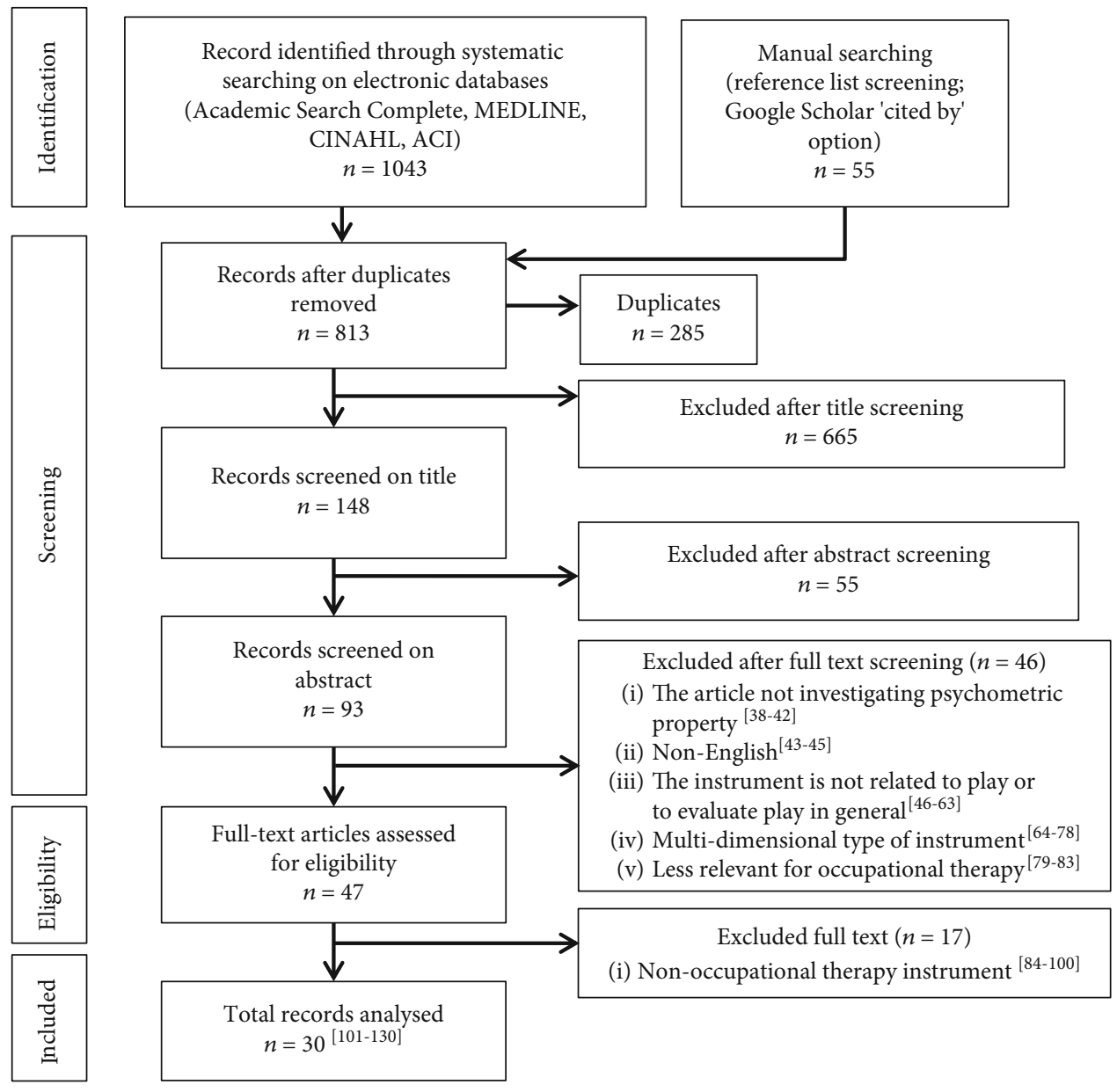

Figure 1: Screening process.

different occasions (i.e., Knox PPS, ToP+TOES, and IChIPPA). Further analysis on the excluded full text articles was also conducted to identify available play instruments and listed in Box 1. However, those instruments are presented for information purpose and not to be included for analysis as they are nonoccupational therapy play instruments.

Instruments found usually investigated for concurrent and construct validity and interrater and test-retest reliability. Some instruments such as Knox PPS have been investigated on the same psychometric properties (e.g., interrater reliability and concurrent validity) over time. Homogeneity on the study location was identified where majority of the instruments have been investigated at the origin country. Most of the origin countries are Caucasian-dominant countries that are heavily influenced by the Western culture. The summary on psychometric evidences of each instrument extracted from individual studies is presented in Table 3.

Several instruments are observation-based (i.e., ChIPPA, ToP, Knox's PPS, and Play Assessment for Group Settings) and evaluated by observing the children in play activities either in real situations or recorded videos, while some are perception-based by rating a questionnaire (i.e., McDonald's Play Inventory, My Child's Play, and Playform), and another is subjective-based instrument that retrieves information from a qualitative interview (i.e., Play History Interview). Most instruments focused on extrinsic elements, such as developmental, behavior and attitude, and skills and performance, except for ToP that views the intrinsic factor (e.g., motivation) of play.

In terms of availability, majority of the instruments are not commercially available. Only the ChIPPA, Knox PPS, and ToP are made commercial. However, ChIPPA is the costliest, whereas the other two are at an affordable range. For the other instruments, contacting the author to obtain the original instrument may be required. The utility description of each instrument is presented in Table 4.

\section{Discussion}

This review found various play instruments where only a small number were developed by an occupational therapist. Some of the instruments were also mentioned and described in the previous reviews [6,9-11], and some of them are newly identified. Clemson and colleagues [131] suggested that an instrument should have at least evidence on content validity and interrater reliability. Conversely, Prinsen et al. [132] specified that an instrument should at least establish a psychometric evidence on content validity, followed by the internal structure of the instrument (i.e., structural validity, 


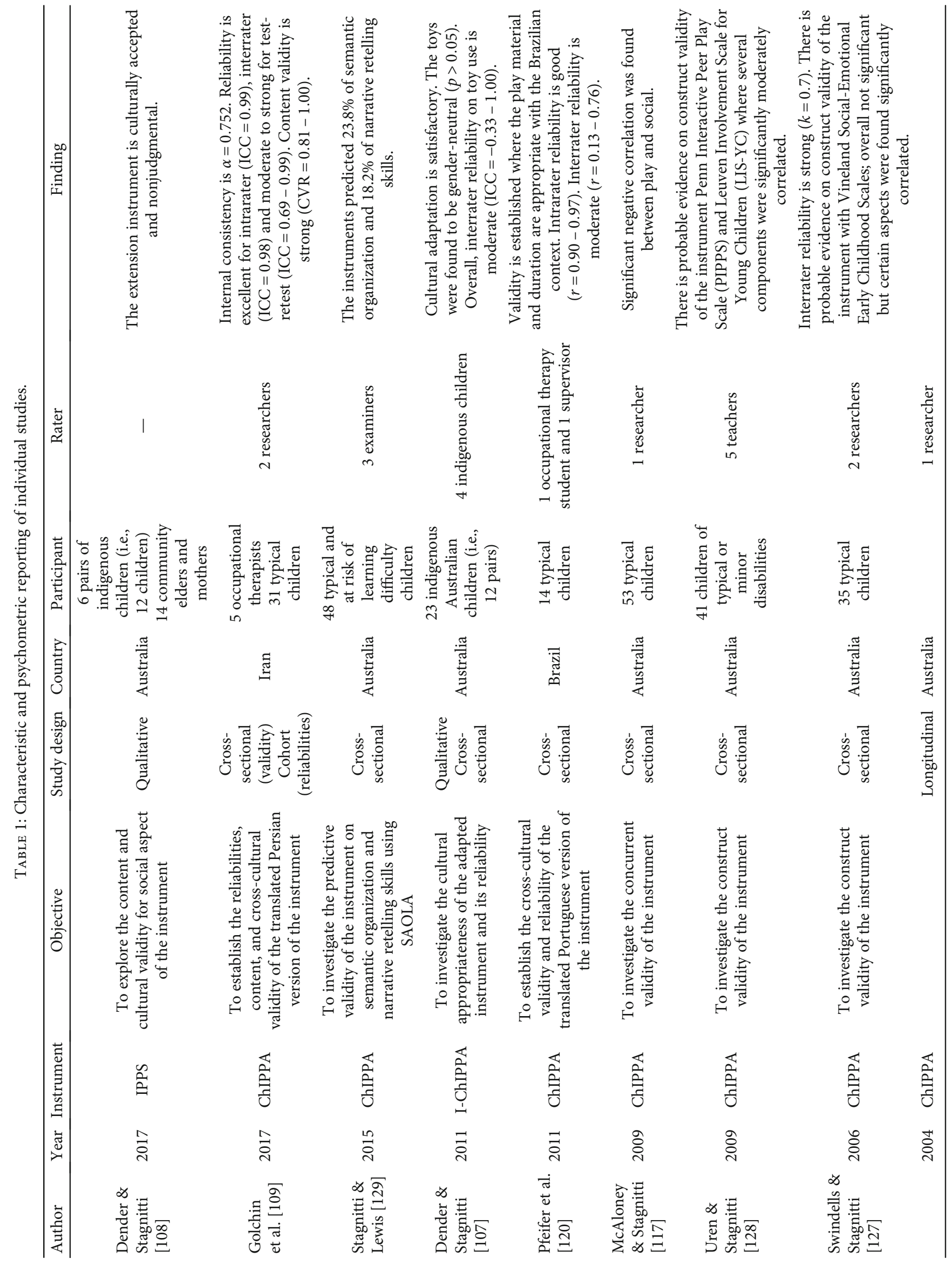




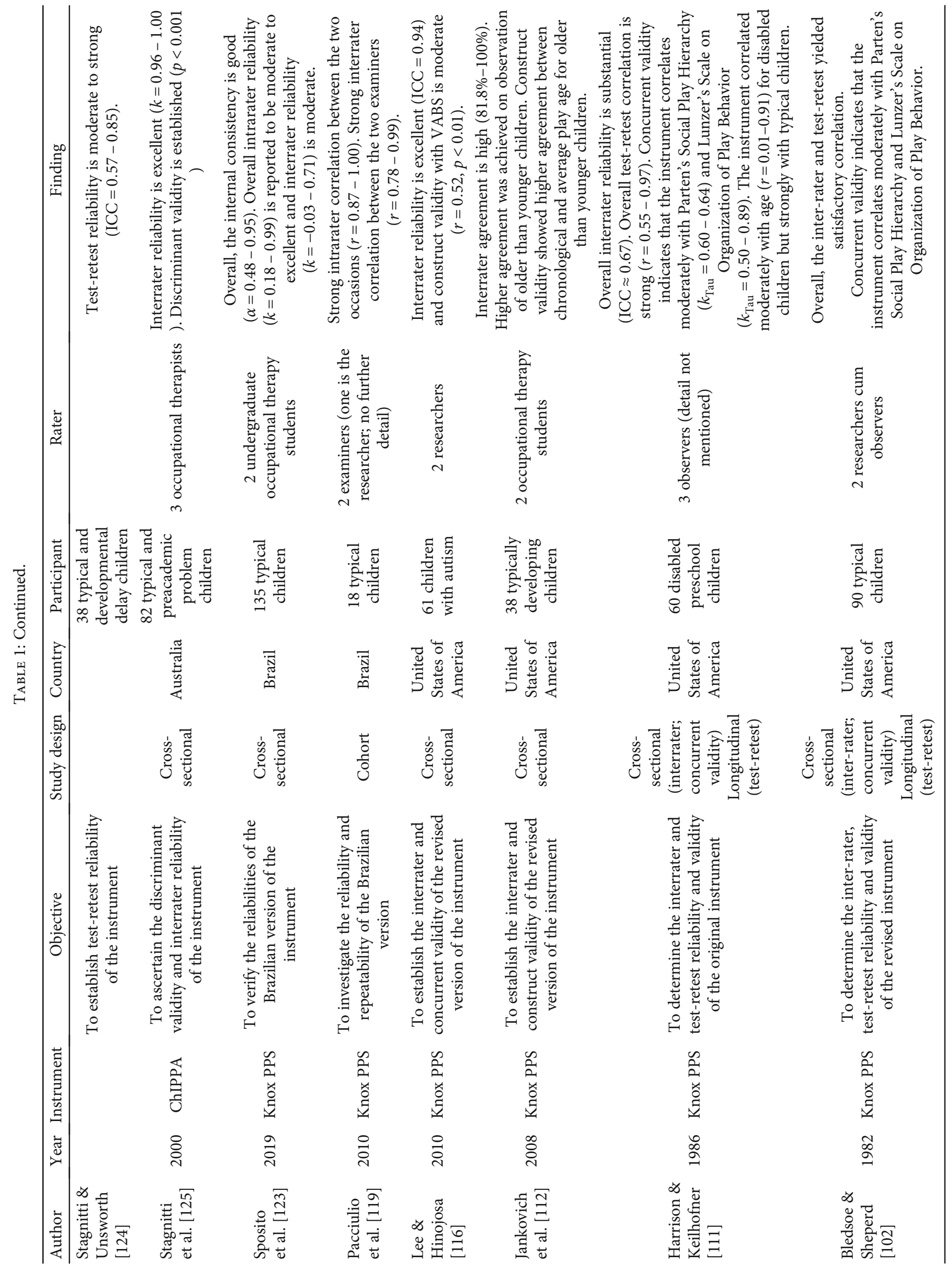




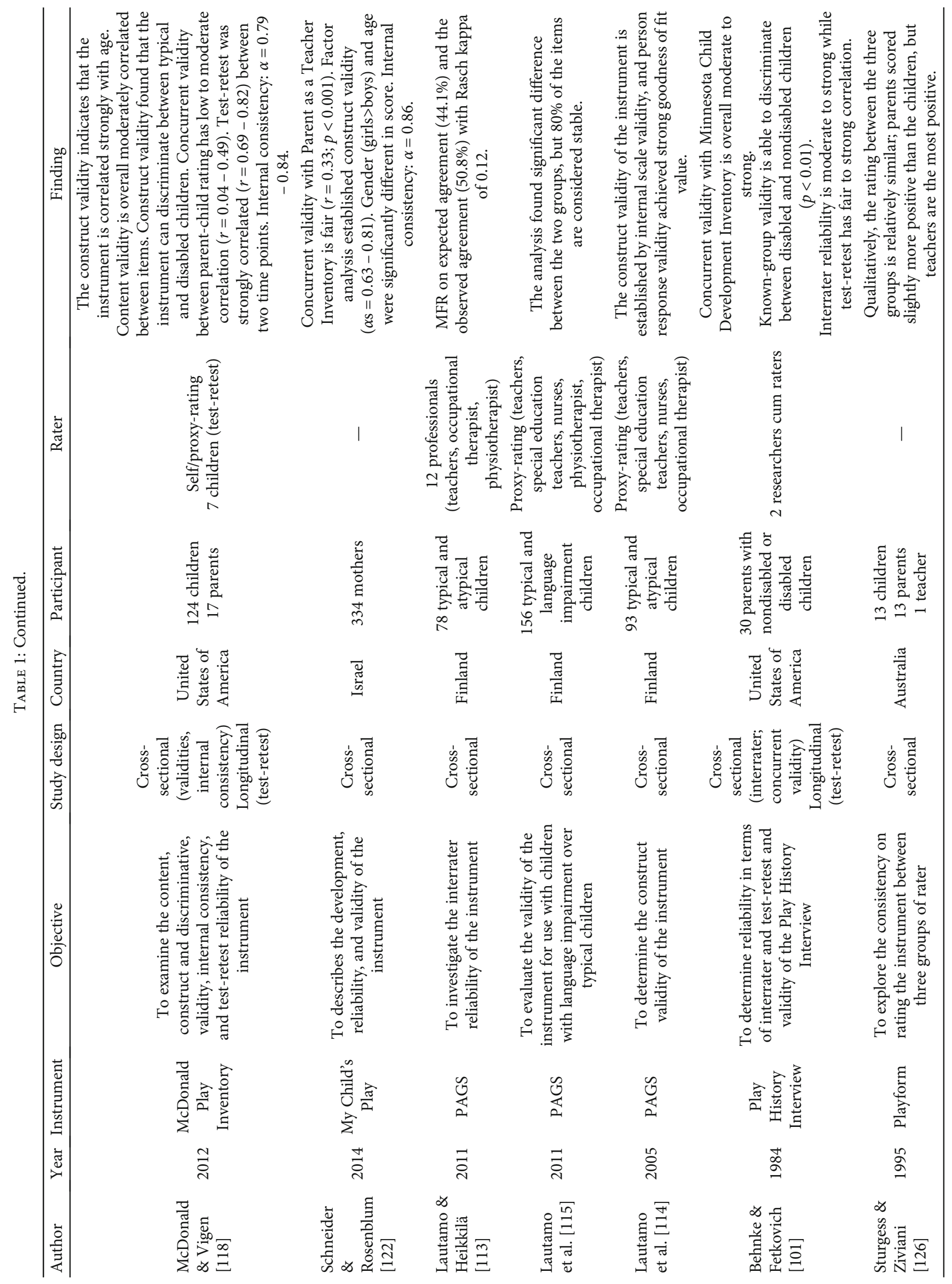




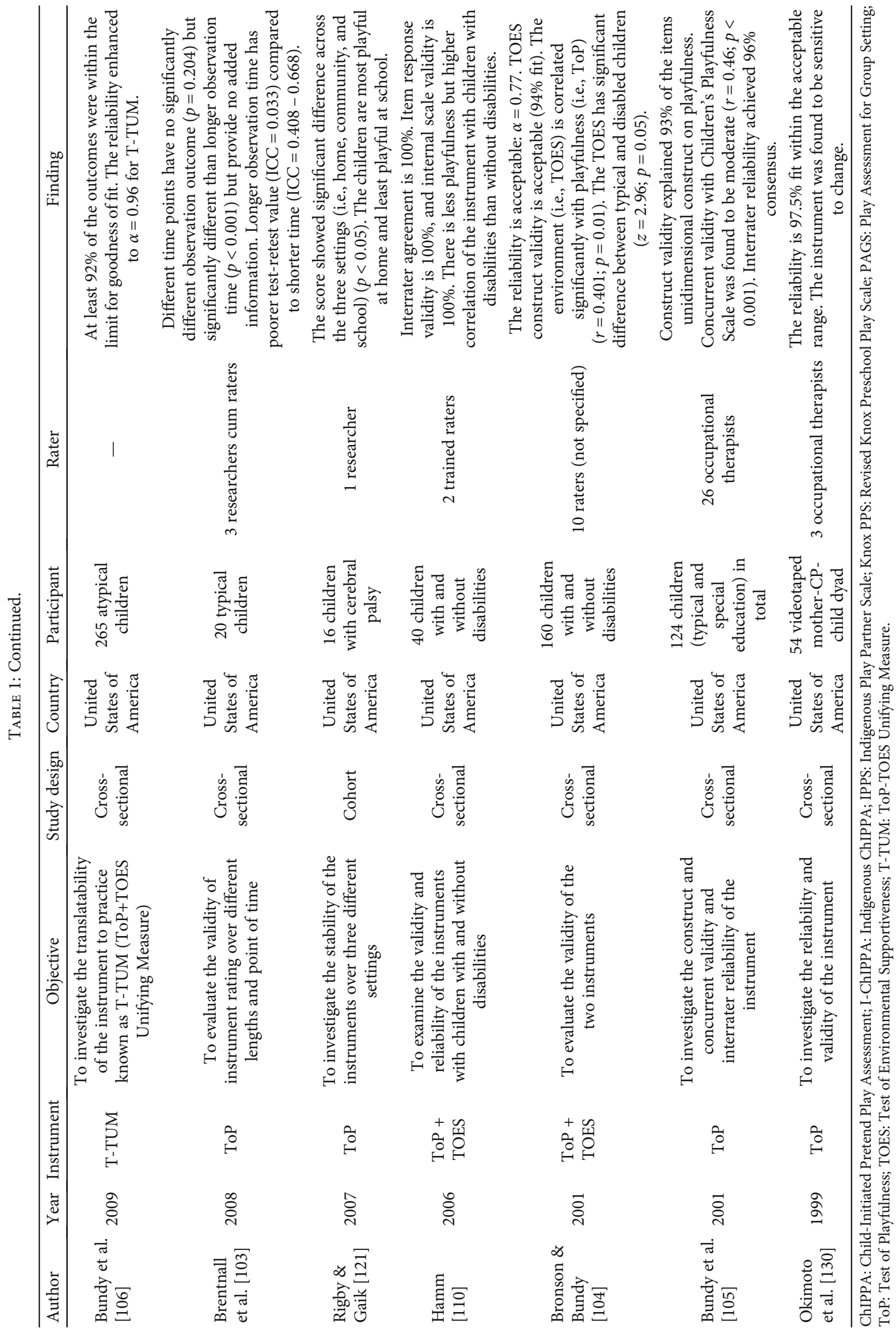


TABLE 2: Quality assessment on each included study using Law and MacDermid [24] tool.

\begin{tabular}{|c|c|c|c|c|c|c|c|c|c|c|c|c|c|c|}
\hline Studies & Instrument $^{\diamond}$ & $\begin{array}{c}\text { Evalu } \\
\text { Item } \\
1\end{array}$ & $\begin{array}{c}\text { tion c } \\
\text { Item } \\
2\end{array}$ & $\begin{array}{c}\text { iteria }^{\dagger} \\
\text { Item } \\
3\end{array}$ & $\begin{array}{c}\text { score: } \\
\text { Item } \\
4\end{array}$ & $\begin{array}{c}2=\text { goo } \\
\text { Item } \\
5\end{array}$ & $\begin{array}{c}\mathrm{d}, 1= \\
\text { Item } \\
6\end{array}$ & $\begin{array}{c}\text { nodera } \\
\text { Item } \\
7\end{array}$ & $\begin{array}{c}\text { te, } 0= \\
\text { Item } \\
8\end{array}$ & $\begin{array}{c}\text { poor, } \mathrm{N} \\
\text { Item } \\
9\end{array}$ & $\begin{array}{c}\mathrm{J} / \mathrm{A}=\mathrm{n} \\
\text { Item } \\
10\end{array}$ & $\begin{array}{c}\text { ot appl } \\
\text { Item } \\
11\end{array}$ & $\begin{array}{c}\text { (cable) } \\
\text { Item } \\
12\end{array}$ & $\begin{array}{c}\text { Total } \\
\text { score }(\%)\end{array}$ \\
\hline $\begin{array}{l}\text { Dender \& Stagnitti } \\
{[108]}\end{array}$ & IPPS & 2 & 2 & 2 & 1 & 1 & N/A & 2 & 2 & 2 & 2 & 0 & 2 & 82 \\
\hline Golchin et al. [109] & ChIPPA & 2 & 2 & 1 & 2 & 2 & 1 & 2 & 1 & 1 & 2 & 2 & 1 & 79 \\
\hline Stagnitti et al. [125] & ChIPPA & 2 & 2 & 2 & 1 & 0 & $\mathrm{~N} / \mathrm{A}$ & 2 & 2 & 2 & 2 & 0 & 2 & 77 \\
\hline $\begin{array}{l}\text { Stagnitti \& Lewis } \\
{[129]}\end{array}$ & ChIPPA & 2 & 2 & 2 & 0 & 0 & N/A & 2 & 2 & 2 & 2 & 0 & 1 & 68 \\
\hline $\begin{array}{l}\text { Uren \& Stagnitti } \\
{[128]}\end{array}$ & ChIPPA & 2 & 1 & 2 & 0 & 0 & N/A & 2 & 2 & 2 & 2 & 0 & 1 & 64 \\
\hline $\begin{array}{l}\text { Swindells \& Stagnitti } \\
\text { [127] }\end{array}$ & ChIPPA & 2 & 0 & 2 & 0 & 0 & N/A & 2 & 2 & 1 & 2 & 2 & 1 & 64 \\
\hline $\begin{array}{l}\text { Stagnitti \& Unsworth } \\
{[124]}\end{array}$ & ChIPPA & 1 & 1 & 1 & 0 & 0 & 2 & 2 & 2 & 2 & 2 & 1 & 1 & 63 \\
\hline $\begin{array}{l}\text { Dender \& Stagnitti } \\
\text { [107] }\end{array}$ & I-ChIPPA & 1 & 2 & 2 & 1 & 0 & N/A & 1 & 1 & 1 & 2 & 0 & 2 & 59 \\
\hline Pfeifer et al. [120] & ChIPPA & 2 & 1 & 1 & 1 & 0 & $\mathrm{~N} / \mathrm{A}$ & 2 & 2 & 1 & 1 & 0 & 2 & 59 \\
\hline $\begin{array}{l}\text { McAloney \& } \\
\text { Stagnitti [117] }\end{array}$ & ChIPPA & 1 & 1 & 2 & 0 & 0 & N/A & 2 & 2 & 2 & 1 & 1 & 1 & 59 \\
\hline Sposito et al. [123] & Knox PPS & 2 & 2 & 1 & 1 & 2 & $\mathrm{~N} / \mathrm{A}$ & 2 & 1 & 1 & 2 & 0 & 2 & 73 \\
\hline Jankovich et al. [112] & Knox PPS & 2 & 2 & 2 & 1 & 0 & N/A & 2 & 2 & 2 & 1 & 0 & 2 & 73 \\
\hline Lee \& Hinojosa [116] & Knox PPS & 2 & 2 & 2 & 1 & 0 & N/A & 1 & 1 & 1 & 2 & 0 & 2 & 64 \\
\hline $\begin{array}{l}\text { Bledsoe \& Sheperd } \\
\text { [102] }\end{array}$ & Knox PPS & 2 & 2 & 2 & 2 & 1 & 0 & 1 & 1 & 2 & 1 & 0 & 1 & 63 \\
\hline $\begin{array}{l}\text { Harrison \& } \\
\text { Keilhofner [111] }\end{array}$ & Knox PPS & 1 & 2 & 1 & 2 & 0 & 1 & 1 & 1 & 2 & 1 & 0 & 1 & 54 \\
\hline Pacciulio et al. [119] & Knox PPS & 2 & 1 & 1 & 1 & 0 & N/A & 1 & 1 & 1 & 1 & 0 & 1 & 45 \\
\hline $\begin{array}{l}\text { McDonald \& Vigen } \\
\text { [118] }\end{array}$ & $\begin{array}{l}\text { McDonald Play } \\
\text { Inventory }\end{array}$ & 2 & 2 & 1 & 2 & 1 & 0 & 2 & 1 & 2 & 1 & 0 & 1 & 63 \\
\hline $\begin{array}{l}\text { Schneider \& } \\
\text { Rosenblum [120] }\end{array}$ & My Child's play & 1 & 1 & 1 & 2 & 1 & N/A & 2 & 0 & 1 & 2 & 1 & 2 & 64 \\
\hline Lautamo et al. [115] & PAGS & 2 & 2 & 2 & 0 & 1 & N/A & 2 & 2 & 2 & 2 & 2 & 2 & 86 \\
\hline $\begin{array}{l}\text { Lautamo \& Heikkilä } \\
\text { [113] }\end{array}$ & PAGS & 2 & 1 & 2 & 0 & 1 & N/A & 2 & 2 & 2 & 2 & 1 & 2 & 77 \\
\hline Lautamo et al. [114] & PAGS & 2 & 1 & 2 & 0 & 1 & N/A & 2 & 1 & 2 & 2 & 2 & 2 & 77 \\
\hline $\begin{array}{l}\text { Behnke \& Fetkovich } \\
\text { [101] }\end{array}$ & $\begin{array}{l}\text { Play history } \\
\text { interview }\end{array}$ & 2 & 2 & 2 & 2 & 0 & 0 & 2 & 1 & 2 & 1 & 0 & 2 & 67 \\
\hline $\begin{array}{l}\text { Sturgess \& Ziviani } \\
\text { [126] }\end{array}$ & Playform & 2 & 2 & 1 & 0 & 0 & N/A & 1 & 2 & 1 & 0 & 0 & 1 & 45 \\
\hline Bundy et al. [106] & T-TUM & 1 & 2 & 2 & 1 & 1 & N/A & 2 & 2 & 2 & 2 & 1 & 2 & 82 \\
\hline $\begin{array}{l}\text { Bronson \& Bundy } \\
{[104]}\end{array}$ & ToP + TOES & 2 & 2 & 2 & 2 & 1 & N/A & 2 & 2 & 1 & 1 & 1 & 2 & 82 \\
\hline Hamm [110] & ToP + TOES & 2 & 2 & 2 & 2 & 0 & N/A & 2 & 2 & 1 & 1 & 1 & 2 & 77 \\
\hline Bundy et al. [105] & ToP & 2 & 2 & 2 & 2 & 1 & $\mathrm{~N} / \mathrm{A}$ & 2 & 2 & 1 & 1 & 0 & 2 & 77 \\
\hline Brentnall et al. [103] & ToP & 2 & 1 & 2 & 1 & 0 & 2 & 1 & 2 & 2 & 2 & 1 & 2 & 75 \\
\hline Rigby \& Gaik [121] & ToP & 2 & 2 & 2 & 0 & 0 & N/A & 2 & 2 & 1 & 1 & 0 & 1 & 59 \\
\hline Okimoto et al. [130] & ToP & 2 & 2 & 1 & 0 & 0 & N/A & 1 & 1 & 2 & 1 & 0 & 1 & 50 \\
\hline
\end{tabular}

${ }^{\dagger}$ Item 1: relevant background on psychometric properties and research question; item 2: inclusion/exclusion criteria; item 3: specific psychometric hypothesis; item 4: appropriate scope of psychometric properties; item 5: appropriate sample size; item 6: appropriate retention/follow-up; item 7: specific descriptions of the measures (administration, scoring, interpretation procedures); item 8: standardization of methods; item 9: data presented for each hypothesis or purpose; item 10: appropriate statistical tests; item 11: appropriate secondary analyses; and item 12: conclusions/clinical recommendations supported by analyses and results. ${ }^{`}$ ChIPPA: Child-Initiated Pretend Play Assessment; I-ChIPPA: Indigenous ChIPPA; IPPS: Indigenous Play Partner Scale; Knox PPS: Revised Knox Preschool Play Scale; PAGS: Play Assessment for Group Setting; ToP: Test of Playfulness; TOES: Test of Environmental Supportiveness; T-TUM: ToPTOES Unifying Measure. 
- Adult Playfulness Scale

- Children's Active Play Imagery Questionnaire

- Children's Developmental Play Instrument

- Children's Play Therapy Instrument

- Children's Playfulness Scale

- Enjoyment of Lunchtime Play Survey Cards

- Fair Play Questionnaire

- Howes Peer Play Scale

- Lowenfeld World Technique

- Lunzer's Play Scale

- Mature Make-Believe Play Observational Instrument

- Modified Revised Class Play

- Parten's Social Play Hierarchy

- Penn Interactive Peer Play Scale

- Perception of Play Questionnaire for Older People

- Play Behaviour Observation System

- Play Performance Scale

- Playfulness Scale for Adults

- Singer's Observational Play Instructions and Imaginative Play Predisposition Interview

- Symbolic Play Test

- The Play Checklist

- The Social Play Record

- The test of Pretend Play (a.k.a. Warwick Symbolic Play Test)

- Transdisciplinary Play-Based Assessment-Child Development Resources

Box 1: Excluded play instruments.

TABLE 3: Summary of the quality of psychometric properties of the instruments.

\begin{tabular}{|c|c|c|c|c|c|c|c|c|c|}
\hline \multirow[b]{2}{*}{ Instrument tool } & \multicolumn{9}{|c|}{ Terwee checklist [25] (score: $+=$ positive; $?=$ intermediate; $-=$ poor; $0=$ no information available) } \\
\hline & $\begin{array}{l}\text { Content } \\
\text { validity }\end{array}$ & $\begin{array}{c}\text { Internal } \\
\text { consistency }\end{array}$ & $\begin{array}{l}\text { Criterion } \\
\text { validity }\end{array}$ & $\begin{array}{c}\text { Construct } \\
\text { validity }\end{array}$ & $\begin{array}{l}\text { Reprodu } \\
\text { Agreement }\end{array}$ & $\begin{array}{l}\text { Reibility } \\
\text { Reliability }\end{array}$ & Responsiveness & $\begin{array}{c}\text { Floor or } \\
\text { ceiling effect }\end{array}$ & Interpretability \\
\hline ChIPPA & $+^{\mathrm{a}},+^{\mathrm{b}},+^{\mathrm{c}}$ & $?^{\mathrm{b}}$ & 0 & ? & ?, ? & $?, ?^{\mathrm{a}}, ?^{\mathrm{b}}$ & 0 & 0 & 0 \\
\hline Knox's PPS & ? & $?^{\mathrm{d}}$ & 0 & ? & ? &,$+ ?^{\mathrm{d}}$ & 0 & 0 & 0 \\
\hline $\begin{array}{l}\text { McDonald Play } \\
\text { Inventory }\end{array}$ & 0 & $?$ & 0 & - & 0 & $?$ & 0 & 0 & 0 \\
\hline My Child's Play & + & + & 0 & + & 0 & 0 & 0 & 0 & 0 \\
\hline PAGS & + & 0 & 0 & + & 0 & + & 0 & 0 & 0 \\
\hline $\begin{array}{l}\text { Play History } \\
\text { Interview }\end{array}$ & $?$ & 0 & 0 & $?$ & $?$ & $?$ & 0 & 0 & 0 \\
\hline Playform & + & 0 & 0 & 0 & 0 & 0 & 0 & 0 & 0 \\
\hline $\begin{array}{l}\text { ToP + TOES, } \\
\text { T-TUM }\end{array}$ & $++^{\mathrm{e}},+^{\mathrm{f}},+^{\mathrm{g}}$ & $+{ }^{\mathrm{f}},+^{\mathrm{g}}$ & 0 & $++^{\mathrm{e}},+{ }^{\mathrm{f}},+^{\mathrm{g}}$ & $?^{e}, ?^{f}$ & $?^{\mathrm{e}}, ?^{\mathrm{f}}$ & 0 & 0 & $?^{\mathrm{f}},+^{\mathrm{g}}$ \\
\hline
\end{tabular}

${ }^{a}$ Brazilian-Portuguese ChIPPA; ${ }^{b}$ Iranian ChIPPA; ${ }^{c}$ Indigenous Play Partner Scale (I-PPS); ${ }^{\mathrm{d}}$ Knox's Play Scale; ${ }^{\mathrm{e}}$ Test of Playfulness (ToP); ${ }^{\mathrm{f}}$ Test of Environmental Supportiveness (TOES); ${ }^{\mathrm{g}}$ ToP-TOES Unifying Measure (T-TUM).

internal consistency, and cross-cultural validity). The instruments found in this review had at least basic psychometric property. However, when compared to other functionbased instruments for children [8], the play instruments found have limited number of psychometric properties investigated. The psychometric investigation of the instruments was mostly around interrater reliability and content validity. Therefore, investigation on the other psychometric properties is warranted. In addition, the methodological quality of the studies is moderate. Aspects such as sample characteristics of the population type, number, size of the cli- ent participants and assessor participants, and generalizability can further be improved.

Several occupational therapy play instruments are recommended based on occasion. The Revised Knox Preschool Play Scale is considered the gold standard for occupational therapy play assessment and suitable to be used to evaluate extrinsic aspect of play. The Revised Knox Preschool Play Scale is an all-rounder that covers an extensive number of domains. Moreover, it is the most common play instrument tool used by occupational therapists and considered easy to administer [16]. In addition, the instrument is accepted 


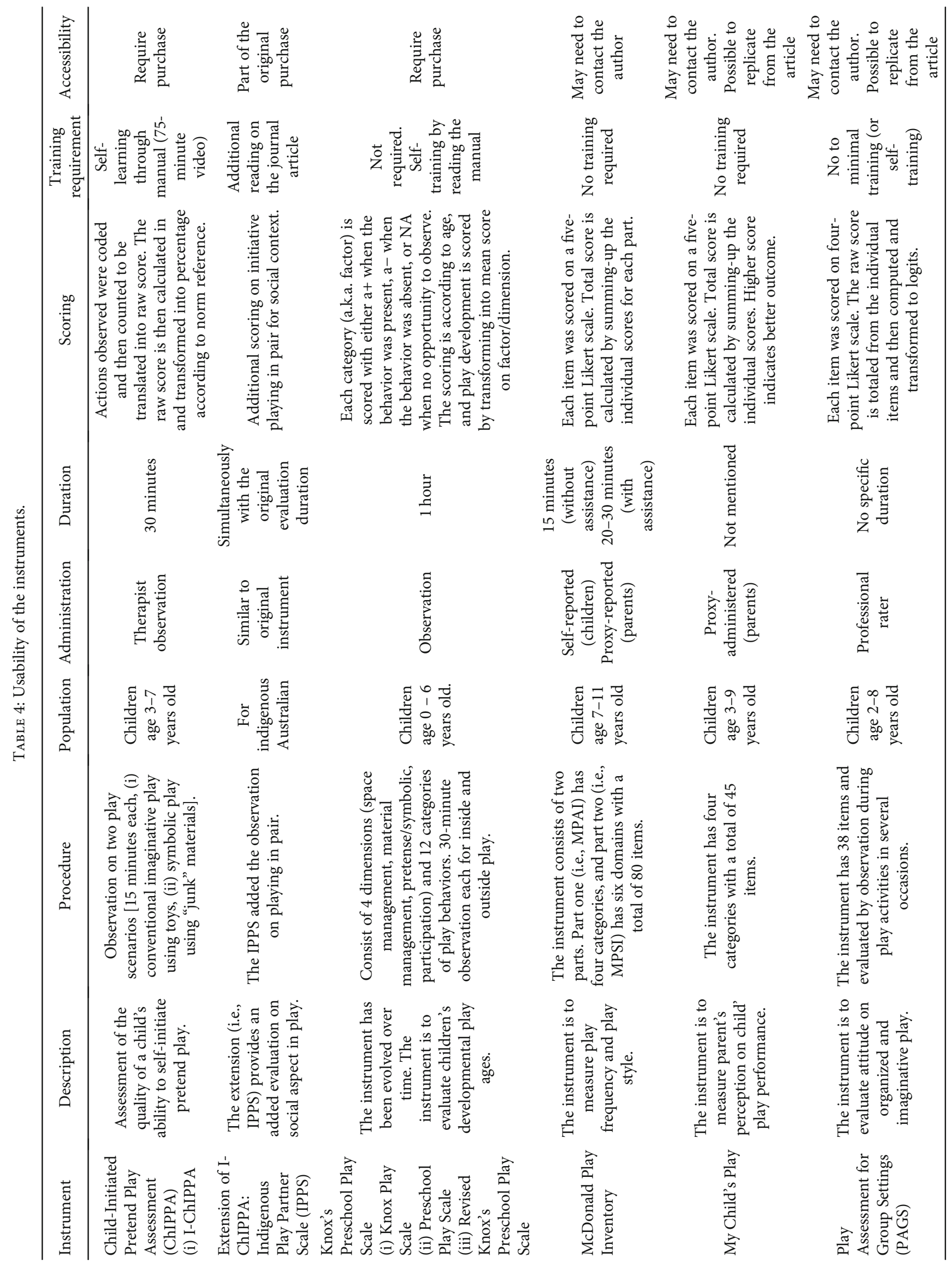




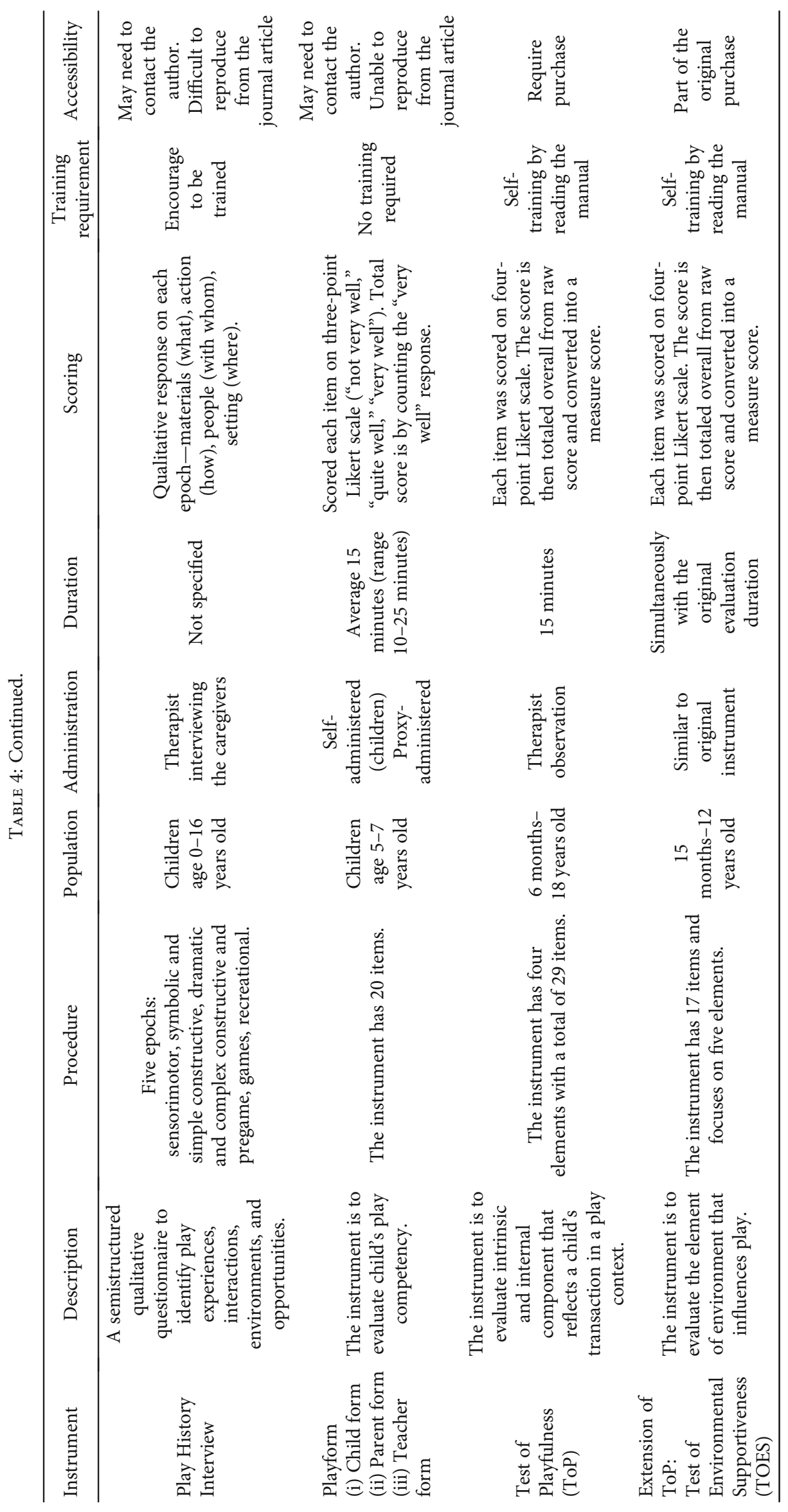


across discipline such as psychologist and speech therapist, thereby becoming a good communication tool between disciplines. The Test of Playfulness and its extension, the Test of Environmental Supportiveness, are a unique instrument that can be used across the widest age range and evaluate the internal element of play, such as motivation; however, the latest innovation of instruments, known as ToP-TOES Unifying Measure (T-TUM), is a promising play instrument. The Revised Knox Preschool Play Scale and Test of Playfulness utilized observation. Observation provides qualitative findings that are useful and valuable for practitioners to complement their evaluation finding on the quantitative outcome [17]. However, using observational instruments may be less favorable for busy practitioners and on setting with various constrains [6]. Therefore, a questionnaire-based instrument is sought, and the My Child's Play instrument can be potentially used for this purpose. The selection of those instruments over the others considers the balance on the clinimetric properties. Psychometric evidence only does not guarantee an instrument application in practice; clinical utility of the instruments also plays a crucial role $[28,133]$. Nevertheless, play instruments in occupational therapy remain immature and evolving; therefore, several potentials and opportunities are available to explore a new instrument development or improve the currently available instruments.

Play is an activity that may be influenced by geosociocultural environment surrounding a person [6, 17]. Cultural value may impose a meaning on an activity, including play. For example, a study by Dender and Stagnitti [107] found that indigenous children appreciate animal toys that resemble their culture compared to the common commercialized farm animal toys. Moreover, children struggle to perform pretend play using the given "scrap" materials because the material is foreign to their culture. In addition, the indigenous children also have difficulty to play alone as mostly the play activity happen in pair or group in the indigenous culture. Most instruments were developed in a developed and Western-influenced country, such as Australia and the United States. Thus, using an instrument developed in one culture to another distinct cultural group may unfairly disadvantage the latter one [134]. The accuracy of an instrument may be reduced; however, improper remedial of the instrument to suit another cultural need may affect the validity of the instrument where it cannot inform any group evaluated. The cross-cultural investigation on functional instrument tools for children is emphasized and warranted [135]. Limited investigation on cross-cultural validity has restricted the widespread applicability of play instruments internationally. Therefore, the usability of play instruments can widely be investigated among cross-countries.

Authorship bias may exist from included studies, and this may compromise the report quality of the article. Involvement of the developer or creator of the instrument in the included studies may have contributed toward bias on the discussion of findings such as emphasizing on positive arguments and suppressing negative outcomes [136]. Only the Knox PPS was found to minimize the impact of the authorship bias; all included studies on Knox PPS have little to no involvement of the original developer of the instrument.
Involvement of the original developer has its benefits such as encouraging the promotion and research on the particular instrument but may be associated with challenges such as the aforementioned bias. Hence, any conflict of interest and funding disclosure should be properly addressed [137]. Readers should cautiously assess the information to ensure reaching a neutral decision.

The clinical utility is another aspect that should be considered besides the psychometric property of an instrument. Although this review did not extensively search for clinical utility, majority of instruments embedded a report on the clinical utility of instruments such as the ChIPPA (see Pfeifer et al. [120]). Some instruments such as Test of Playfulness reported the clinical utility in a separate publication [138]. Clinical utility aspects that warranted attention from researchers are on appropriateness (e.g., importance of clinical decision-making and impact on the existing treatment process), accessibility (e.g., cost-effectiveness, availability, and support by peer-professionals and organizations), practicability (e.g., suitability across settings and professional and training requirement), and acceptability (e.g., ethical, social, or psychological concern) [139]. Most of the publications reported the duration of administration and training requirement. However, explicit clinical utility should be reported together with the psychometric property publication of the instruments. This will increase the relevancy of instruments to be used by practitioners.

Majority of play instruments focused on preschool and school-aged children; limited for newborns, infants, and toddlers; and negligible for adolescents. While play is known as the dominant activity for children, its essence is available across lifespan $[6,140,141]$. The neglected populations are somewhat denied on their right to play. Other disciplines such as psychology have carefully considered this approach. For example, the Fair Play Questionnaire is a generic instrument that evaluates the social and ethical opportunity of adolescents in play participation especially in structured play [86]. Other studies investigated instruments to evaluate the playfulness among older people $[83,99]$. As the developmental stages become more mature such as adolescents and adults, play concept usually inhibited and replaced with leisure [140], and this is where play evaluation is not a priority. For example, Henry [60] and Trottier et al. [63] examined the instrument on leisure aspect of adolescents as this concept becomes the main focus compared to play during this stage of the lifespan. However, play element should continue to be investigated across the lifespan.

4.1. Implication to Practice. Play has been argued as a complex construct and influenced by relative multidimensionality. Only a study by Rigby and Gaik [121] investigated the stability of measuring play in several settings (i.e., home, community, and school) which found that it may influence the playful experience but not exclusive to the specific type of setting. For example, one child may experience the highest level of playfulness at home and lowest at school, whereas another child may experience otherwise. Another study by Kielhofner et al. [41] showed that environmental setting and involved personnel significantly contribute toward the 
play quality. This warranted an attention to consider the environment as a mediating factor. Hence, among the play instruments found in this review, T-TUM has successfully addressed the issue of environmental effects but may require further investigation. On the other hand, a study by Hyndman et al. [100] indicate that play perception varies between days in a week and varies on happiness level perception before and after the play. This aspect was not extensively investigated in any occupational therapy play instrument. This information should be crucially considered when conducting play assessment to ensure consistent outcome and interpretation.

In practice, practitioners require an instrument that can provide information on extensive number of aspects, requires minimal training and low administrative burden, and is easy to interpret [21, 142]. However, occupational therapy practitioners should consider both characteristics (i.e., skills) and quality traits (i.e., enjoyment) on play either during the evaluation or intervention. Planning a play activity as intervention may support or inhibit the progression of clients depending on the appropriateness of planning. Using an appropriate standardized assessment is one of the ways to facilitate proper and evidence-based planning [21]. Having a good standardized assessment may provide confidence to practitioners in rationalizing the service $[19,20]$. However, play is associated with various ambiguities, and the current development of existing instruments on play is limited to one small part of play as mentioned by Bundy [17] — "reducing play to skills" (p. 99) - that is unable to provide a holistic picture on the client's play condition. To address the current limitations, practitioners should exercise good clinical reasoning skills. Synthesizing the objective outcome (i.e., standardized assessment result) with clinical reasoning (i.e., values and belief) will strengthen the planning that benefits the client $[6,17,143]$. Therefore, practitioners should combine findings from the instrument with clinical reasoning for a better service.

4.2. Limitation and Recommendation. This systematic review has several limitations to be noted. First, articles included were only obtained from journal publications, and therefore, evidence on psychometric properties of the instrument may not be comprehensive. Several psychometric evidences such as content validity may be available in the manual instrument book such as ChIPPA [144]. Several instruments are only available in grey literature format that is not captured during the review search. For example, the Kid and Preteen Play Profile can be found in a book [145]. Second, the review only included publication in English language. Several articles found in this review were in foreign languages but excluded due to the limited ability to understand the articles. This is associated with disadvantages involving instruments that provide more psychometric evidences, especially on crosscultural applicability. Third, some psychometric properties of the instrument are briefly reported as a small part of the original study (see, for example, Okimoto et al. [130]), which compromise reporting on the quality and inability to provide a detailed description on the psychometric evidence. Fourth, the use of Terwee's checklist is still not comprehensive enough to illustrate the available type of psychometric prop- erties. Even the COSMIN taxonomy [132] does not provide the available extensive type of validity and reliability. According to Law and MacDermid [24], more than 25 types of validities and reliabilities were found. Therefore, future research may try to investigate other types of validity and reliability that can be added on the number of psychometric evidence of the instruments besides the existing ones. Nevertheless, this review can provide a comprehensive guideline for practitioners to select an appropriate play instrument in practice.

\section{Conclusions}

Several play assessments are available for occupational therapists used in practice. Outcome from standardized play instrument may convince stakeholders and clients to change their perception on play as a main goal for children rehabilitation. However, the current development of play instruments is immature and constantly evolving. Available instruments are constantly developed and continue to be improved. Nevertheless, several instruments such as the Revised Knox Preschool Play Scale are suitably used as a comprehensive play evaluation for extrinsic perspective of play. The Test of Playfulness + Test of Environmental Supportiveness Unifying Measure is promising in evaluating intrinsic perspectives of play. As both instruments utilized an observation approach, My Child's Play is a potential instrument for a questionnaire-based reported outcome. However, practitioners need to consider several aspects such as client's needs, support, and facility condition and exercise good clinical reasoning when selecting an instrument for use.

\section{Conflicts of Interest}

The authors declare no conflict of interest.

\section{Acknowledgments}

The protocol for this systematic review was registered on INPLASY (202040156) and is available in full on http:// inplasy.com/ (doi:10.37766/inplasy2020.4.0156) as well as on PROSPERO (CRD42020170370). There were no requirements for an ethical review of this paper since no human participants were involved.

\section{References}

[1] I. Novak and I. Honan, "Effectiveness of paediatric occupational therapy for children with disabilities: a systematic review," Australian Occupational Therapy Journal, vol. 66, no. 3, pp. 258-273, 2019.

[2] H. R. Cornell, T. T. Lin, and J. A. Anderson, "A systematic review of play-based interventions for students with ADHD: implications for school-based occupational therapists," Journal of Occupational Therapy, Schools, \& Early Intervention, vol. 11, no. 2, pp. 192-211, 2018.

[3] H. Kuhaneck, S. L. Spitzer, and S. C. Bodison, "A systematic review of interventions to improve the occupation of play in 
children with autism," OTJR: Occupation, Participation and Health, vol. 40, no. 2, pp. 83-98, 2020.

[4] A. A. Schottelkorb, K. L. Swan, and Y. Ogawa, "Intensive child-centered play therapy for children on the autism spectrum: a pilot study," Journal of Counseling \& Development, vol. 98, no. 1, pp. 63-73, 2020.

[5] N. R. R. Gomes, E. C. Maia, and I. V. D. Varga, "Os benefícios do brincar para a saúde das crianças: uma revisão sistemática," Arquivos de Ciências da Saúde, vol. 25, no. 2, pp. 4751,2018 .

[6] K. Stagnitti, "Understanding play: the implications for play assessment," Australian Occupational Therapy Journal, vol. 51, no. 1, pp. 3-12, 2004.

[7] G. Romagnoli, A. Leone, G. Romagnoli et al., "Occupational therapy's efficacy in children with Asperger's syndrome: a systematic review of randomized controlled trials," La Clinica Terapeutica, vol. 170, no. 5, pp. e382-e387, 2019.

[8] M. H. Romli, F. Wan Yunus, and L. Mackenzie, "Overview of reviews of standardised occupation-based instruments for use in occupational therapy practice," Australian Occupational Therapy Journal, vol. 66, no. 4, pp. 428-445, 2019.

[9] J. L. Sturgess, "Current trends in assessing children's play," British Journal of Occupational Therapy, vol. 60, no. 9, pp. 410-414, 2016.

[10] T. Brown and H. Bourke-Taylor, "Children and youth instrument development and testing articles published in the American Journal of Occupational Therapy,2009-2013: a content, methodology, and instrument design review," American Journal of Occupational Therapy, vol. 68, no. 5, pp. e154e216, 2014.

[11] C. L. Hilton, S. E. Goloff, O. Altaras, and N. Josman, "Review of instrument development and testing studies for children and youth," American Journal of Occupational Therapy, vol. 67, no. 3, pp. e30-e54, 2013.

[12] M. G. O'Grady and S. C. Dusing, "Reliability and validity of play-based assessments of motor and cognitive skills for infants and young children: a systematic review," Physical Therapy, vol. 95, no. 1, pp. 25-38, 2015.

[13] K. Lifter, S. Foster-Sanda, C. Arzamarski, J. Briesch, and E. McClure, "Overview of play," Infants \& Young Children, vol. 24, no. 3, pp. 225-245, 2011.

[14] B. N. Thompson and T. R. Goldstein, "Disentangling pretend play measurement: defining the essential elements and developmental progression of pretense," Developmental Review, vol. 52, no. 1, pp. 24-41, 2019.

[15] S. Ray-Kaeser, S. Châtelain, V. Kindler, and E. Schneider, "2 The evaluation of play from occupational therapy and psychology perspectives," in Evaluation of childrens' play: Tools and Methods, S. Besio, D. Bulgarelli, and V. Stancheva-Popkostadinova, Eds., pp. 19-57, De Gruyter, Warsaw, Poland, 2018.

[16] H. M. Kuhaneck, K. J. Tanta, A. K. Coombs, and H. Pannone, "A survey of pediatric occupational therapists' use of play," Journal of Occupational Therapy, Schools, \& Early Intervention, vol. 6, no. 3, pp. 213-227, 2013.

[17] A. Bundy, "Evidence to practice commentary: beware the traps of play assessment," Physical \& Occupational Therapy in Pediatrics, vol. 30, no. 2, pp. 98-100, 2010.

[18] H. Lynch, M. Prellwitz, C. Schulze, and A. H. Moore, "The state of play in children's occupational therapy: a comparison between Ireland, Sweden and Switzerland," British
Journal of Occupational Therapy, vol. 81, no. 1, pp. 4250, 2017.

[19] C. C. Wadley and K. Stagnitti, "The views and experiences of teachers, therapists and integration aides of play-based programs within specialist school settings," Journal of Occupational Therapy, Schools, \& Early Intervention, pp. $1-14,2020$.

[20] C. A. Unsworth, "Evidence-based practice depends on the routine use of outcome measures," British Jounal of Occupational Therapy, vol. 74, no. 5, p. 209, 2011.

[21] E. A. S. Duncan and J. Murray, "The barriers and facilitators to routine outcome measurement by allied health professionals in practice: a systematic review," BMC Health Services Research, vol. 12, no. 1, 2012.

[22] G. A. Fava, E. Tomba, and N. Sonino, "Clinimetrics: the science of clinical measurements," International Journal of Clinical Practice, vol. 66, no. 1, pp. 11-15, 2012.

[23] K. Wright, S. Golder, and R. Rodriguez-Lopez, "Citation searching: a systematic review case study of multiple risk behaviour interventions," BMC Medical Research Methodology, vol. 14, no. 1, 2014.

[24] M. Law and J. Mac Dermid, Evidence-Based Rehabilitation: A Guide to Practice, United States of America: Slack Incorporated, 3rd edition, 2014.

[25] C. B. Terwee, S. D. M. Bot, M. R. de Boer et al., "Quality criteria were proposed for measurement properties of health status questionnaires," Journal of Clinical Epidemiology, vol. 60, no. 1, pp. 34-42, 2007.

[26] C. B. Terwee, L. B. Mokkink, D. L. Knol, R. W. J. G. Ostelo, L. M. Bouter, and H. C. W. de Vet, "Rating the methodological quality in systematic reviews of studies on measurement properties: a scoring system for the COSMIN checklist," Quality of Life Research, vol. 21, no. 4, pp. 651-657, 2012.

[27] H. K. Yuen and S. L. Austin, "Systematic review of studies on measurement properties of instruments for adults published in the American Journal of Occupational Therapy, 20092013," American Journal of Occupational Therapy, vol. 68, no. 3, pp. e97-e106, 2014.

[28] M. H. Romli, L. Mackenzie, M. Lovarini, M. P. Tan, and L. Clemson, "The clinimetric properties of instruments measuring home hazards for older people at risk of falling: a systematic review," Evaluation \& the Health Professions, vol. 41, no. 1, pp. 82-128, 2016.

[29] L. B. Mokkink, C. B. Terwee, D. L. Knol et al., "The COSMIN checklist for evaluating the methodological quality of studies on measurement properties: a clarification of its content," BMC Medical Research Methodology, vol. 10, no. 1, 2010.

[30] L. B. Mokkink, C. B. Terwee, E. Gibbons et al., "Inter-rater agreement and reliability of the COSMIN (consensus-based standards for the selection of health status measurement instruments) checklist," BMC Medical Research Methodology, vol. 10, no. 1, 2010.

[31] V. Flamand, H. Massã@-Alarie, and C. Schneider, "Psychometric evidence of spasticity measurement tools in cerebral palsy children and adolescents: a systematic review," Journal of Rehabilitation Medicine, vol. 45, no. 1, pp. 14-23, 2013.

[32] M. Forhan, B. Vrkljan, and J. MacDermid, "A systematic review of the quality of psychometric evidence supporting the use of an obesity-specific quality of life measure for use with persons who have class III obesity," Obesity Reviews, vol. 11, no. 3, pp. 222-228, 2010. 
[33] J. C. MacDermid, D. M. Walton, S. Avery et al., "Measurement properties of the neck disability index: a systematic review," Journal of Orthopaedic \& Sports Physical Therapy, vol. 39, no. 5, pp. 400-417, 2009.

[34] D. M. Rouleau, K. Faber, and J. C. MacDermid, "Systematic review of patient-administered shoulder functional scores on instability," Journal of Shoulder and Elbow Surgery, vol. 19, no. 8, pp. 1121-1128, 2010.

[35] J. S. Roy, F. Desmeules, and J. MacDermid, "Psychometric properties of presenteeism scales for musculoskeletal disorders: a systematic review," Journal of Rehabilitation Medicine, vol. 43, no. 1, pp. 23-31, 2011.

[36] J. S. Roy, J. C. MacDermid, and L. J. Woodhouse, "Measuring shoulder function: a systematic review of four questionnaires," Arthritis Care \& Research, vol. 61, no. 5, pp. 623-632, 2009.

[37] J. S. Roy, J. C. MacDermid, and L. J. Woodhouse, "A systematic review of the psychometric properties of the ConstantMurley score," Journal of Shoulder and Elbow Surgery, vol. 19, no. 1, pp. 157-164, 2010.

[38] J. M. Hurff, "A Play Skills Inventory: a competency monitoring tool for the 10 year old," American Journal of Occupational Therapy, vol. 34, no. 10, pp. 651-656, 1980.

[39] G. Restall and J. Magill-Evans, "Play and preschool children with Autism," American Journal of Occupational Therapy, vol. 48, no. 2, pp. 113-120, 1994.

[40] C. D. Morrison, A. C. Bundy, and A. G. Fisher, "The contribution of motor skills and playfulness to the play performance of preschoolers," American Journal of Occupational Therapy, vol. 45, no. 8, pp. 687-694, 1991.

[41] G. Kielhofner, R. Barris, D. Bauer, B. Shoestock, and L. Walker, "A comparison of play behavior in nonhospitalized and hospitalized children," American Journal of Occupational Therapy, vol. 37, no. 5, pp. 305-312, 1983.

[42] L. M. Hess and A. C. Bundy, "The association between playfulness and coping in adolescents," Physical \& Occupational Therapy in Pediatrics, vol. 23, no. 2, pp. 5-17, 2009.

[43] Y. Kim and J. Lee, "The development and validation of a playfulness scale for infants \& toddlers," Korean Journal of Child Study, vol. 33, no. 6, pp. 85-107, 2012.

[44] C. Ermert, "Age, sex and diagnosis-specific differences in play of preschool children with the Scenotest: a study of the constructive validity of observation systems," Zeitschrift Fur Klinische Psychologie, Psychopathologie Und Psychotherapie, vol. 42, no. 4, pp. 373-384, 1994.

[45] P. Puttapuan and S. Sriphetcharawut, "Cross cultural validity and reliability of the Kid Play Profile assessment for children aged 6-9 years: Thai version," Journal of Associated Medical Sciences, vol. 50, no. 3, 2017.

[46] A. Agaronov, M. M. Leung, J. M. Garcia et al., "Feasibility and reliability of the System for Observing Play and Leisure Activity in Youth (SOPLAY) for measuring moderate to vigorous physical activity in children visiting an interactive children's museum exhibition," American Journal of Health Promotion, vol. 32, no. 1, pp. 210-214, 2016.

[47] R. Cassibba, M. H. van Ijzendoorn, and L. D'Odorico, "Attachment and play in child care centres: reliability and validity of the attachment Q-sort for mothers and professional caregivers in Italy," International Journal of Behavioral Development, vol. 24, no. 2, pp. 241-255, 2016.

[48] N. Favez, H. Tissot, and F. Frascarolo, "Is it typical? The ecological validity of the observation of mother-father-infant interactions in the Lausanne Trilogue Play," European Journal of Developmental Psychology, vol. 16, no. 1, pp. 113-121, 2017.

[49] C. George and J. Solomon, "The attachment doll play assessment: predictive validity with concurrent mother-child interaction and maternal caregiving representations," Frontiers in Psychology, vol. 7, no. 10, 2016.

[50] N. B. Hamutoğlu, M. Topal, Y. Samur, D. M. Gezgin, and M. D. Griffiths, "The development of the online player type Scale," International Journal of Cyber Behavior, Psychology and Learning, vol. 10, no. 1, pp. 15-31, 2020.

[51] D. Levac, J. Nawrotek, E. Deschenes et al., "Development and reliability evaluation of the movement rating instrument for virtual reality video game play," JMIR Serious Games, vol. 4, no. 1, p. e9, 2016.

[52] T. L. McKenzie, D. A. Cohen, A. Sehgal, S. Williamson, and D. Golinelli, "System for Observing Play and Recreation in Communities (SOPARC): reliability and feasibility measures," Journal of Physical Activity \& Health, vol. 3, no. s1, pp. S208-S222, 2006.

[53] L. N. Niec and S. W. Russ, "Children's internal representations, empathy, and fantasy play: a validity study of the SCORS-Q," Psychological Assessment, vol. 14, no. 3, pp. 331-338, 2002.

[54] D. C. Ray, K. Purswell, S. Haas, and C. Aldrete, "Child-centered play therapy-research integrity checklist: development, reliability, and use," International Journal of Play Therapy, vol. 26, no. 4, pp. 207-217, 2017.

[55] M. P. M. Santos, C. R. Rech, C. O. Alberico et al., "Utility and reliability of an App for the System for Observing Play and Recreation in Communities (iSOPARC ${ }^{\circledR}$ )," Measurement in Physical Education \& Exercise Science, vol. 20, no. 2, pp. 9398, 2016.

[56] A. E. Staiano, M. A. Adams, and G. J. Norman, "Motivation for Exergame Play Inventory: construct validity and relationship to game play," Cyberpsychology, vol. 13, no. 3, pp. 54-66, 2019.

[57] J. A. Stearns, B. Wohlers, T.-L. F. McHugh, N. Kuzik, and J. C. Spence, "Reliability and validity of the PLAYfun tool with children and youth in Northern Canada," Measurement in Physical Education \& Exercise Science, vol. 23, no. 1, pp. 47-57, 2018.

[58] R. A. Tejeiro, J. P. Espada, M. T. Gonzálvez, and P. Christiansen, "Proprietes psychometriques de l'echelle Problem Video Game Playing chez les adultes," Revue Europeenne de Psychologie Appliquee, vol. 66, no. 1, pp. 9-13, 2016.

[59] J. Veitch, J. Salmon, and K. Ball, "The validity and reliability of an instrument to assess children's outdoor play in various locations," Journal of Science \& Medicine in Sport, vol. 12, no. 5, pp. 579-582, 2009.

[60] A. D. Henry, "Development of a measure of adolescent leisure interests," American Journal of Occupational Therapy, vol. 52, no. 7, pp. 531-539, 1998.

[61] G. King, P. Rigby, and L. Avery, "Revised Measure of Environmental Qualities of Activity Settings (MEQAS) for youth leisure and life skills activity settings," Disability \& Rehabilitation, vol. 38, no. 15, pp. 1509-1520, 2015.

[62] G. King, P. Rigby, B. Batorowicz et al., "Development of a direct observation measure of environmental qualities of activity settings," Developmental Medicine \& Child Neurology, vol. 56, no. 8, pp. 763-769, 2014. 
[63] A. N. Trottier, G. T. Brown, S. J. G. Hobson, and W. Miller, "Reliability and validity of the Leisure Satisfaction Scale (LSS - short form) and the Adolescent Leisure Interest Profile (ALIP)," Occupational Therapy International, vol. 9, no. 2, pp. 131-144, 2002.

[64] K. E. Arestad, D. MacPhee, C. Y. Lim, and M. A. Khetani, "Cultural adaptation of a pediatric functional assessment for rehabilitation outcomes research," BMC Health Services Research, vol. 17, no. 1, p. 658, 2017.

[65] F. M. Åström, M. Khetani, and A. K. Axelsson, "Young Children's Participation and Environment Measure: Swedish cultural adaptation," Physical \& Occupational Therapy In Pediatrics, vol. 38, no. 3, pp. 329-342, 2018.

[66] B. Batorowicz, G. King, F. Vane, M. Pinto, and P. Raghavendra, "Exploring validation of a graphic symbol questionnaire to measure participation experiences of youth in activity settings," Augmentative and Alternative Communication, vol. 33, no. 2, pp. 97-109, 2017.

[67] M. K. Bult, O. Verschuren, M. K. Kertoy, E. Lindeman, M. J. Jongmans, and M. Ketelaar, "Psychometric evaluation of the Dutch version of the Assessment of Preschool Children's Participation (APCP): construct validity and test-retest reliability," Physical \& Occupational Therapy In Pediatrics, vol. 33, no. 4, pp. 372-383, 2013.

[68] C. L. Chen, C. Y. Chen, I. H. Shen, I. S. Liu, L. J. Kang, and C. Y. Wu, "Clinimetric properties of the Assessment of Preschool Children's Participation in children with cerebral palsy," Research in Developmental Disabilities, vol. 34, no. 5, pp. 1528-1535, 2013.

[69] C. W. Chien, C. W. P. Li-Tsang, P. P. P. Cheung, K. Y. Leung, and C. Y. Lin, "Development and psychometric evaluation of the Chinese version of the Participation and Environment Measure for Children and Youth," Disability and Rehabilitation, pp. 1-11, 2019.

[70] A. Golos and N. Weintraub, "The psychometric properties of the Structured Preschool Participation Observation (SPO)," Physical \& Occupational Therapy In Pediatrics, pp. 1-13, 2020.

[71] L. J. Kang, A. W. Hwang, R. J. Palisano, G. A. King, L. A. Chiarello, and C. L. Chen, "Validation of the Chinese version of the Assessment of Preschool Children's Participation for children with physical disabilities," Developmental Neurorehabilitation, vol. 20, no. 5, pp. 266-273, 2016.

[72] M. A. Khetani, J. E. Graham, P. L. Davies, M. C. Law, and R. J. Simeonsson, "Psychometric properties of the Young Children's Participation and Environment Measure," Archives of Physical Medicine and Rehabilitation, vol. 96, no. 2, pp. 307-316, 2015.

[73] M. A. Khetani, "Validation of environmental content in the young children's participation and environment measure," Archives of Physical Medicine and Rehabilitation, vol. 96, no. 2, pp. 317-322, 2015.

[74] G. King, B. Batorowicz, P. Rigby, M. McMain-Klein, L. Thompson, and M. Pinto, "Development of a measure to assess youth Self-reported Experiences of Activity Settings (SEAS)," International Journal of Disability, Development and Education, vol. 61, no. 1, pp. 44-66, 2014.

[75] M. Law, G. King, T. Petrenchik, M. Kertoy, and D. Anaby, "The assessment of preschool children's participation: internal consistency and construct validity," Physical \& Occupational Therapy In Pediatrics, vol. 32, no. 3, pp. 272-287, 2011.

[76] C. Y. Lim, M. Law, M. Khetani, N. Pollock, and P. Rosenbaum, "Establishing the cultural equivalence of the
Young Children's Participation and Environment Measure (YC-PEM) for use in Singapore," Physical \& Occupational Therapy In Pediatrics, vol. 36, no. 4, pp. 422-439, 2016.

[77] C. Y. Lim, M. Law, M. Khetani, P. Rosenbaum, and N. Pollock, "Psychometric evaluation of the Young Children's Participation and Environment Measure (YC-PEM) for use in Singapore," Physical \& Occupational Therapy In Pediatrics, vol. 38, no. 3, pp. 316-328, 2018.

[78] U. Williams, M. Law, S. Hanna, and J. W. Gorter, "Using the Young Children's Participation and Environment Measure (YC-PEM) to describe young children's participation and relationship to disability and complexity," Journal of Developmental and Physical Disabilities, vol. 31, no. 1, pp. 135-148, 2019.

[79] A. Aydin, "Turkish adaptation of Test of Pretended Play," Educational Sciences: Theory \& Practice, vol. 12, no. 2, pp. 916-925, 2012.

[80] E. Delvecchio, D. Mabilia, J. B. Li, and D. di Riso, "Pretend play in Italian children: validation of the Affect in Play Scale-Preschool version," Journal of Child and Family Studies, vol. 25, no. 1, pp. 86-95, 2016.

[81] K. K. Fehr and S. W. Russ, "Assessment of pretend play in preschool-aged children: validation and factor analysis of the Affect in Play Scale-Preschool Version," Journal of Personality Assessment, vol. 96, no. 3, pp. 350-357, 2013.

[82] S. Keleş and Ö. Yurt, "An investigation of playfulness of preschool children in Turkey," Early Child Development and Care, vol. 187, no. 8, pp. 1372-1387, 2017.

[83] C. Yarnal and X. Qian, "Older-adult playfulness: an innovative construct and measurement for healthy aging research," American Journal of Play, vol. 4, no. 1, pp. 52-79, 2011.

[84] A. E. Aleva, F. A. Goossens, P. H. Dekker, and O. M. Laceulle, "The reliability and validity of a modified revised class play examined in Dutch elementary-school children," European Journal of Psychological Assessment, vol. 33, no. 6, pp. 475485, 2017.

[85] R. J. Bulotsky-Shearer, L. M. López, and J. L. Mendez, "The validity of interactive peer play competencies for Latino preschool children from low-income households," Early Childhood Research Quarterly, vol. 34, pp. 78-91, 2016.

[86] E. Buzi, J. Jarani, and E. Isidori, "Pro-social and antisocial values in physical education: the validity and reliability of Fair Play Questionnaire in physical education (FPQ-PE) into Albanian language," Physical Activity Review, vol. 7, pp. 143-151, 2019.

[87] S. E. Chazan, "The Children's Developmental Play Instrument (CDPI): a validity study," International Journal of Play, vol. 1, no. 3, pp. 297-310, 2012.

[88] S. E. Chazan and Y. A. Kuchirko, "The Children's Developmental Play Instrument (CDPI): an extended validity study," Journal of Infant, Child, and Adolescent Psychotherapy, vol. 16, no. 3, pp. 234-244, 2017.

[89] S. E. Chazan and Y. A. Kuchirko, “Observing children's play activity using the Children's Developmental Play Instrument (CDPI): a qualitative validity study," Journal of Infant, Child, and Adolescent Psychotherapy, vol. 18, no. 1, pp. 71-92, 2019.

[90] V. Farmer-Dougan and T. Kaszuba, "Reliability and validity of play-based observations: relationship between the PLAY behaviour observation system and standardised measures of cognitive and social skills," International Journal of Phytoremediation, vol. 19, no. 4, pp. 429-440, 1999. 
[91] G. A. Fix and C. Schaefer, "Note on psychometric properties of playfulness scales with adolescents," Psychological Reports, vol. 96, 3_suppl, pp. 993-994, 2016.

[92] C. Germeroth, E. Bodrova, C. Day-Hess et al., "Play it high, play it low: examining the reliability and validity of a new observation tool to measure children's make-believe play," American Journal of Play, vol. 11, no. 2, pp. 183-221, 2019.

[93] V. R. Hampton and J. W. Fantuzzo, "The validity of the Penn Interactive Peer Play Scale with urban, low-income kindergarten children," School Psychology Review, vol. 32, no. 1, pp. 77-91, 2003.

[94] V. O. Kashani, B. G. Mohamadi, and M. Mokaberian, "Psychometric properties of the Persian version of children's active play imagery questionnaire," Annals of Applied Sport Science, vol. 5, no. 4, pp. 49-59, 2017.

[95] P. F. Kernberg, S. E. Chazan, and L. Normandin, "The Children's Play Therapy Instrument (CPTI): description, development, and reliability studies," Journal of Psychotherapy Practice and Research, vol. 7, no. 3, pp. 196-207, 1998.

[96] T. A. May-Benson, A. Teasdale, M. Hung et al., "Interrater reliability of the Jarrold, Boucher and Smith play scenario," American Journal of Occupational Therapy, vol. 70, 4_Supplement_1, p. 7011500051p1, 2016.

[97] C. L. Myers, S. L. McBride, and C. A. Peterson, "Transdisciplinary, play-based assessment in early childhood special Education," Topics in Early Childhood Special Education, vol. 16, no. 1, pp. 102-126, 2016.

[98] E. Trevlas, V. Grammatikopoulos, N. Tsigilis, and E. Zachopoulou, "Evaluating playfulness: construct validity of the Children's Playfulness Scale," Early Childhood Education Journal, vol. 31, no. 1, pp. 33-39, 2003.

[99] M. M. Y. Tse, T. S. Kwan, and P. H. Lee, "The development and psychometric evaluation of the Perception of Play Questionnaire for older adults," Educational Gerontology, vol. 42, no. 2, pp. 79-88, 2015.

[100] B. P. Hyndman, et al.A. C. Benson, S. Ullah, C. F. Finch, and A. Telford, “Children's Enjoyment of Play During School Lunchtime Breaks: An Examination of Intraday and Interday Reliability," Journal of Physical Activity and Health, vol. 11, no. 1, pp. 109-117, 2014.

[101] C. J. Behnke and M. M. Fetkov, "Examining the Reliability and Validity of the Play History," American Journal of Occupational Therapy, vol. 38, no. 2, pp. 94-100, 1984.

[102] N. P. Bledsoe and J. T. Shepherd, "A study of reliability and validity of a Preschool Play Scale," American Journal of Occupational Therapy, vol. 36, no. 12, pp. 783-788, 1982.

[103] J. Brentnall, A. C. Bundy, F. Catherine, and S. Kay, "The effect of the length of observation on Test of Playfulness scores," OTJR: Occupation, Participation and Health, vol. 28, no. 3, pp. 133-140, 2008.

[104] M. R. Bronson and A. C. Bundy, "A correlational study of a Test of Playfulness and a Test of Environmental Supportiveness for play," The Occupational Therapy Journal of Research, vol. 21, no. 4, pp. 241-259, 2016.

[105] A. C. Bundy, L. Nelson, M. Metzger, and K. Bingaman, "Validity and reliability of a test of playfulness," The Occupational Therapy Journal of Research, vol. 21, no. 4, pp. 276292, 2016.

[106] A. C. Bundy, K. Waugh, and J. Brentnall, "Developing assessments that account for the role of the environment: an example using the Test of Playfulness and Test of Environmental
Supportiveness," OTJR: Occupation, Participation and Health, vol. 29, no. 3, pp. 135-143, 2009.

[107] A. Dender and K. Stagnitti, "Development of the Indigenous Child-Initiated Pretend Play Assessment: selection of play materials and administration," Australian Occupational Therapy Journal, vol. 58, no. 1, pp. 34-42, 2011.

[108] A. M. Dender and K. E. Stagnitti, "Content and cultural validity in the development of the Indigenous Play Partner Scale," Australian Occupational Therapy Journal, vol. 64, no. 4, pp. 283-293, 2017.

[109] M. D. Golchin, N. Mirzakhani, K. Stagnitti, M. D. Golchin, and M. Rezaei, "Psychometric properties of Persian version of 'child-initiated pretend play assessment' for Iranian children," Iranian Journal of Pediatrics, vol. 27, article e7053, pp. 1-8, 2016.

[110] E. M. Hamm, "Playfulness and the environmental support of play in children with and without developmental disabilities," OTJR: Occupation, Participation and Health, vol. 26, no. 3, pp. 88-96, 2016.

[111] H. Harrison and G. Kielhofner, "Examining reliability and validity of the Preschool Play Scale with handicapped children," American Journal of Occupational Therapy, vol. 40, no. 3, pp. 167-173, 1986.

[112] M. Jankovich, J. Mullen, E. Rinear, K. Tanta, and J. Deitz, "Revised Knox Preschool Play Scale: interrater agreement and construct validity," American Journal of Occupational Therapy, vol. 62, no. 2, pp. 221-227, 2008.

[113] T. Lautamo and M. Heikkilä, "Inter-rater reliability of the Play Assessment for Group Settings," Scandinavian Journal of Occupational Therapy, vol. 18, no. 1, pp. 3-10, 2010.

[114] T. Lautamo, A. Kottorp, and A. L. Salminen, "Play assessment for group settings: a pilot study to construct an assessment tool," Scandinavian Journal of Occupational Therapy, vol. 12, no. 3, pp. 136-144, 2009.

[115] T. Lautamo, M. L. Laakso, T. Aro, T. Ahonen, and K. Törmäkangas, "Validity of the Play Assessment for Group Settings: an evaluation of differential item functioning between children with specific language impairment and typically developing peers," Australian Occupational Therapy Journal, vol. 58, no. 4, pp. 222-230, 2011.

[116] S. C. Lee and J. Hinojosa, "Inter-rater reliability and concurrent validity of the Preschool Play Scale with preschool children with autism spectrum disorders," Journal of Occupational Therapy, Schools, \& Early Intervention, vol. 3, no. 2, pp. 154-167, 2010.

[117] K. McAloney and K. Stagnitti, "Pretend play and social play: the concurrent validity of the Child-Initiated Pretend Play Assessment," International Journal of Play Therapy, vol. 18, no. 2, pp. 99-113, 2009.

[118] A. E. McDonald and C. Vigen, "Reliability and validity of the McDonald Play Inventory," American Journal of Occupational Therapy, vol. 66, no. 4, pp. e52-e60, 2012.

[119] A. M. Pacciulio, L. I. Pfeifer, and J. L. F. Santos, "Preliminary reliability and repeatability of the Brazilian version of the Revised Knox Preschool Play Scale," Occupational Therapy International, vol. 17, no. 2, pp. 74-80, 2010.

[120] L. I. Pfeifer, M. A. Queiroz, J. L. F. Santos, and K. E. Stagnitti, "Cross-cultural adaptation and reliability of ChildInitiated Pretend Play Assessment (ChIPPA)," Canadian Journal of Occupational Therapy, vol. 78, no. 3, pp. 187195, 2011. 
[121] P. Rigby and S. Gaik, "Stability of playfulness across environmental Settings," Physical \& Occupational Therapy In Pediatrics, vol. 27, no. 1, pp. 27-43, 2009.

[122] E. Schneider and S. Rosenblum, "Development, reliability, and validity of the My Child's Play (MCP) questionnaire," American Journal of Occupational Therapy, vol. 68, no. 3, pp. 277-285, 2014.

[123] A. M. P. Sposito, J. L. F. Santos, and L. I. Pfeifer, "Validation of the Revised Knox Preschool Play Scale for the Brazilian population," Occupational Therapy International, vol. 2019, Article ID 6397425, 5 pages, 2019.

[124] K. Stagnitti and C. Unsworth, "The test-retest reliability of the Child-Initiated Pretend Play Assessment," American Journal of Occupational Therapy, vol. 58, no. 1, pp. 93-99, 2004.

[125] K. Stagnitti, C. Unsworth, and S. Rodger, "Development of an assessment to identify play behaviours that discriminate between the play of typical preschoolers and preschoolers with pre-academic problems," Canadian Journal of Occupational Therapy, vol. 67, no. 5, pp. 291-303, 2016.

[126] J. Sturgess and J. Ziviani, "Development of a self-report play questionnaire for children aged 5 to 7 years: a preliminary report," Australian Occupational Therapy Journal, vol. 42, no. 3, pp. 107-117, 1995.

[127] D. Swindells and K. Stagnitti, "Pretend play and parents' view of social competence: the construct validity of the ChildInitiated Pretend Play Assessment," Australian Occupational Therapy Journal, vol. 53, no. 4, pp. 314-324, 2006.

[128] N. Uren and K. Stagnitti, "Pretend play, social competence and involvement in children aged 5-7 years: the concurrent validity of the Child-Initiated Pretend Play Assessment," Australian Occupational Therapy Journal, vol. 56, no. 1, pp. 33-40, 2009.

[129] K. Stagnitti and F. M. Lewis, "Quality of pre-school children's pretend play and subsequent development of semantic organization and narrative retelling skills," International Journal of Speech-Language Pathology, vol. 17, no. 2, pp. 148-158, 2014.

[130] A. M. Okimoto, A. Bundy, and J. Hanzlik, "Playfulness in children with and without disability: measurement and intervention," American Journal of Occupational Therapy, vol. 54, no. 1, pp. 73-82, 2000.

[131] L. Clemson, M. H. Fitzgerald, R. Heard, and R. G. Cumming, "Inter-rater reliability of a home fall hazards assessment tool," The Occupational Therapy Journal of Research, vol. 19, no. 2, pp. 83-98, 2016.

[132] C. A. C. Prinsen, L. B. Mokkink, L. M. Bouter et al., "COSMIN guideline for systematic reviews of patient-reported outcome measures," Quality of Life Research, vol. 27, no. 5, pp. 1147-1157, 2018.

[133] M. Yang, X. Ding, and B. Dong, "The Measurement of Disability in the Elderly: A Systematic Review of Self- Reported Questionnaires," Journal of the American Medical Directors Association, vol. 15, no. 2, pp. 150.e1-150.e9, 2014.

[134] S. Paul, "Culture and its influence on occupational therapy evaluation," Canadian Journal of Occupational Therapy, vol. 62, no. 3, pp. 154-161, 2016.

[135] M. Tofani, G. Galeoto, D. Cazzetta, A. Berardi, J. Sansoni, and J. Valente, "Validation of the Pediatric Evaluation of Disability Inventory in an Italian population with autism spectrum disorder: a cross-sectional study," La Clinica Terapeutica, vol. 170, no. 6, pp. e460-e464, 2019.
[136] J. P. Singh, M. Grann, and S. Fazel, “Authorship bias in violence risk assessment? a systematic review and meta-analysis," PLoS One, vol. 8, no. 9, article e72484, 2013.

[137] F. Davidoff, C. DeAngelis, J. M. Drazen et al., "Sponsorship, authorship, and accountability," New England Journal of Medicine, vol. 345, no. 11, pp. 825-827, 2001.

[138] D. Cameron, M. Leslie, R. Teplicky et al., "The clinical utility of the Test of Playfulness," Canadian Journal of Occupational Therapy, vol. 68, no. 2, pp. 104-111, 2016.

[139] A. Smart, "A multi-dimensional model of clinical utility," International Journal for Quality in Health Care, vol. 18, no. 5, pp. 377-382, 2006.

[140] C. Essame, "Developmental play: a new approach to understanding how all children learn through play," Childhood Education, vol. 96, no. 1, pp. 14-23, 2020.

[141] H. Lynch and A. Moore, "Play as an occupation in occupational therapy," British Journal of Occupational Therapy, vol. 79, no. 9, pp. 519-520, 2016.

[142] T. Stapleton and C. McBrearty, "Use of standardised assessments and outcome measures among a sample of Irish occupational therapists working with adults with physical disabilities," British Journal of Occupational Therapy, vol. 72, no. 2, pp. 55-64, 2009.

[143] C. Unsworth and A. Baker, "A systematic review of professional reasoning literature in occupational therapy," British Journal of Occupational Therapy, vol. 79, no. 1, pp. 5-16, 2016.

[144] K. Stagnitti, The Child-Initiated Pretend Play Assessment 2: ChIPPA 2, Learn to Play, Melbourne, Australia, 2020.

[145] A. Henry, Assessment of play and leisure in children and adolescents, in Play in Occupational Therapy for Children, L. D. Parham and L. Fazio, Eds., United States of America, Mosby, 2008. 